Published as: Curr Opin Plant Biol. 2011 April ; 14(2): 116-122.

\title{
Histone variants and modifications in plant gene regulation
}

\author{
Roger B. Deal ${ }^{1}$ and Steven Henikoff ${ }^{1,2,{ }^{*}}$ \\ ${ }^{1}$ Basic Sciences Division, Fred Hutchinson Cancer Research Center, Seattle, WA 98109, USA \\ ${ }^{2}$ Howard Hughes Medical Institute, Seattle, WA 98109, USA
}

\section{Summary}

Genomes are packaged by complexing DNA with histone proteins, which provides an opportunity to regulate gene expression by dynamically impeding access of transcriptional regulatory proteins and RNA polymerases to DNA. The incorporation of histone variants into nucleosomes and addition of post-translational modifications to histones can alter the physical properties of nucleosomes and thereby serve as a mechanism for regulating DNA exposure. Chromatin-based gene regulation has profound effects on developmental processes including regulation of the vegetative to reproductive transition, as well as responses to pathogens and abiotic factors. Incorporation of the histone variant $\mathrm{H} 2 \mathrm{~A} . \mathrm{Z}$ and methylation of histone $\mathrm{H} 3$ lysine residues 4 and 27 have emerged as key elements in the regulation of genes involved in each of these processes.

\section{Introduction}

The eukaryotic genome is tightly wrapped by histones to form nucleosomes, which must be densely packed to fit within the small volume of the nucleus. Despite these packaging constraints, nucleosomes must be able to allow access of sequence-specific binding proteins and enzymes such as DNA and RNA polymerases to DNA. Nucleosomes are composed of $\sim 150$ bp of DNA coiled around an octameric histone core particle containing two copies of each of the four core histone proteins (H2A, H2B, H3 and H4) [1,2]. The properties of a nucleosome can be altered in several ways, including replacement of canonical histones with specialized variant types, post-translational modification of histones, movement of the histone core relative to the underlying DNA sequence, and partial or complete removal of histones from the DNA. Chromatin-based gene regulation is effected by the interplay between sequence-specific DNA binding proteins, histone variants, histone modifying enzymes, chromatin-associated proteins, and ATP-dependent nucleosome remodelers, but how all of these components work together is still unclear [3]. An emerging view is that the composition of a nucleosome in terms of histone variants and histone post-translational modifications (PTMs) dictates its physical stability and propensity to be slid along the DNA or removed completely [4]. In this way, pathways directed at altering these nucleosome characteristics can be used to regulate exposure and occlusion of the DNA. This review will focus on recent advances in understanding histone variants and post-translational modifications (PTMs) and their roles in regulating gene expression during plant development and in response to the environment.

\footnotetext{
() 2010 Elsevier Ltd. All rights reserved.

*Corresponding author: steveh@fhcrc.org.
}

Publisher's Disclaimer: This is a PDF file of an unedited manuscript that has been accepted for publication. As a service to our customers we are providing this early version of the manuscript. The manuscript will undergo copyediting, typesetting, and review of the resulting proof before it is published in its final citable form. Please note that during the production process errors may be discovered which could affect the content, and all legal disclaimers that apply to the journal pertain. 


\section{Histone variants}

In addition to the major histones, which are deposited during DNA replication, all eukaryotes have variant types of $\mathrm{H} 2 \mathrm{~A}$ and $\mathrm{H} 3$ that are incorporated into chromatin during interphase and can impart unique properties to the nucleosomes they occupy [5]. The H2A variants $\mathrm{H} 2 \mathrm{AX}$ and $\mathrm{H} 2 \mathrm{~A} . \mathrm{Z}$ are both found in plants, and multiple isoforms of each are present [6]. H2AX is phosphorylated on its unique C-terminal serine at sites of DNA damage and is involved in orchestrating the DNA repair pathway [7]. The role of this variant in repair pathways has been extensively studied in animals and it is presumed to play a similar role in plants [8], but has not been studied at a functional level.

The H2A.Z variant differs from H2A by many amino acid substitutions throughout the length of the protein, particularly in the C-terminal a-helical region [9]. This variant has been studied in yeast, animals, and plants, and has been implicated in many different genomic processes including transcriptional regulation, maintenance of genome integrity, and the formation of heterochromatin boundaries [10]. Genome-wide profiling of the location of H2A.Z by chromatin immunoprecipitation coupled to microarrays (ChIP-chip) has revealed that this variant is widespread throughout genomes and, as a rule, found in nucleosomes flanking the transcriptional start site (TSS) [11-13], where it appears to play a role in transcriptional regulation, at least in part, by helping to prevent DNA methylation $[13,14]$. H2A.Z is inserted into nucleosomes by the yeast Swr1 ATP-dependent nucleosome remodeling complex and by related complexes in animals and plants, which partially unwrap the nucleosome and replace an H2A/H2B dimer with an H2A.Z/H2B dimer [15]. Multiple H2A.Z variants and a SWR1-like deposition complex are found in plants, and these regulate many genes involved in both development and environmental responses, as discussed below.

Two variants of $\mathrm{H} 3$ are found in all eukaryotes: $\mathrm{CenH} 3$ and $\mathrm{H} 3.3$. The CenH3 variant is incorporated at centromeres and is essential for chromosome segregation, as discussed in the review by $\mathbf{X}$ et al. in this issue. The H3.3 variant differs from $\mathrm{H} 3$ at only 3 to 4 amino acids in both plants and animals [16] and is deposited into chromatin outside of DNA replication through different histone chaperones, including HirA and Daxx, depending on the genomic location [17-19]. Deposition of H3.3 into chromatin occurs predominantly within promoters, transcribed regions of expressed genes, and at gene regulatory elements, where nucleosomes are being rapidly disrupted and replaced [20,21].

In animals, H2A.Z and H3.3 show partially overlapping genome-wide distributions in which both variants are enriched near the TSS and in gene body nucleosomes at the $5^{\prime}$ end of expressed genes [20,22]. Nucleosomes containing H2A.Z but not H3.3 are relatively stable, whereas those that contain both variants are prone to disassembly in vivo [23]. These unstable double-variant nucleosomes are found near TSSs and so may modulate exposure of promoter DNA by promoting nucleosome turnover [24]. Multiple isoforms of H3.3 exist in plants, but none of these have yet been mapped genome-wide or studied functionally. However, the Arabidopsis homolog of the H3.3 chaperone HirA has been shown to mediate silencing of $K N O X$ genes during leaf development [25], presumably through $\mathrm{H} 3.3$ deposition. Whether this is the result of a direct effect of $\mathrm{H} 3.3$ on the $K N O X$ genes themselves is unknown.

\section{Histone post-translational modifications}

Biochemical studies of histone proteins have shown that they can be extensively modified post-translationally at their $\mathrm{N}$-terminal tails through the addition of acetyl, methyl, phosphoryl and ADP-ribose groups, as well as peptides such as SUMO and ubiquitin. Genome-wide mapping of these modified histones has revealed that certain groups of 
histone modifications tend to co-occur in a given region, and each PTM can be broadly categorized as being associated with actively transcribed genes, silenced genes, or transposons $[3,26,27]$. In particular, acetylation and methylation of $\mathrm{H} 3$ lysine residues play roles in promoting the expression or silencing, as well as switching between these states, of many genes in both plants and animals. With some exceptions, the types of histone modifications that occur, as well as their functions, are generally conserved between plants and animals [28].

Acetylation of histones alters the physical properties of nucleosomes directly by loosening association between histones and DNA, whereas other PTMs, including methylation, often create binding sites for other proteins that have specific effects on chromatin-based processes. In the case of modifications that are bound by specific effector proteins, these can either be involved in the repression of transcription by mechanisms such as compacting nucleosome arrays [29,30], or they can support transcription by recruiting chromatin remodeling complexes, modifying enzymes, or other complexes involved in elongation or splicing [31,32].

Two well-studied $\mathrm{H} 3$ methyl modifications are trimethylation of $\mathrm{H} 3$ lysine 4 (H3K4me3) and trimethylation of $\mathrm{H} 3$ lysine 27 (H3K27me3), which are correlated with transcriptional activation and silencing, respectively. $\mathrm{H} 3 \mathrm{~K} 4 \mathrm{me} 3$ is enriched at the $5^{\prime}$ end of actively transcribed genes by the enzymatic action of trithorax group (trxG) protein complexes associated with the initiation form of RNA polymerase [33]. Similar distributions of this modification are found in the genomes of Arabidopsis, rice, and Maize [34-36].

Nucleosomes carrying this modification are recognized by multiple protein complexes including histone acetyltransferases as well as the Chd1 and NURF complexes, which can remodel nucleosomes to support ongoing transcription [37]. Chd1 can also recruit the RNA splicing machinery to facilitate the coordination of transcription and splicing [32]. Thus, trimethylation of $\mathrm{H} 3 \mathrm{~K} 4$ facilitates transcription, and this effect can be reversed through the targeted action of specific H3K4 demethylase enzymes in order to silence a gene [38].

In contrast to $\mathrm{H} 3 \mathrm{~K} 4 \mathrm{me} 3, \mathrm{H} 3 \mathrm{~K} 27 \mathrm{me} 3$ is associated with stable silencing of developmentally important genes in both animals and plants. In animals, this modification is catalyzed by the Polycomb Repressive 2 (PRC2) complex and is found over regions many kilobases in size, often covering developmentally regulated genes. This modification is recognized by the Polycomb Repressive 1 (PRC1) complex, which acts to condense chromatin and thereby repress transcription $[39,40]$. In plants, this modification also appears to be deposited by one or more homologs of the PRC2 complex. Unlike in animals, H3K27me3 is generally restricted to promoters and transcribed regions of individual genes in plants, and is found at roughly $15-20 \%$ of genes in Arabidopsis [41,42] and 30-40\% of genes in rice and Maize $[35,36]$. Furthermore, H3K27me3 in Arabidopsis is bound by LIKE HETEROCHROMATIN PROTEIN 1 (LHP1), which is related to animal HETEROCHROMATIN PROTEIN 1 (HP1) [43,44]. LHP1 and several plant homologs of animal PRC1 components appear to form a PRC1-like silencing complex [45]. In addition, the plant-specific protein EMBRYONIC FLOWER 1 (EMF1) also plays a PRC1-like role in silencing the floral homeotic gene AGAMOUS ( $A G$ ) [46], suggesting that plants have other mechanisms for PcG silencing in addition to the PRC1 complex itself.

\section{The vegetative to reproductive transition}

In recent years, breakthroughs have been made in understanding the roles of H2A.Z and PTMs such as H3K4me3 and H3K27me3 in plant gene regulation. Perhaps the best understood example of the role of plant histone variants and PTMs in gene regulation is that of the Arabidopsis FLOWERING LOCUS C (FLC) gene, which controls the transition from 
vegetative growth to flowering. The $F L C$ gene is expressed during the vegetative growth phase and acts to repress the transition to flowering by reducing the expression of genes that promote flowering, thus $F L C$ must be silenced for flowering to occur. The expression of $F L C$ during vegetative growth and its silencing prior to flowering is an excellent example of the interplay between trxG activators and PcG silencing proteins, as well as the histone variant H2A.Z and other chromatin modifications in both stabilizing and switching between the active and silent states (Figure 1).

During vegetative growth the expression of $F L C$ is promoted through the deposition of H3K4me3 by the Arabidopsis Paf1 complex and other trxG proteins [47-49], and incorporation of H2A.Z by the SWR1-like complex [50-53]. Loss of Paf1 complex members, the trithorax group ATX proteins, subunits of the SWR1 complex, or H2A.Z itself all lead to reduced $F L C$ expression and premature flowering. In addition to these components, other modifications to $F L C$ chromatin, including H3 acetylation, H2B ubiquitination, and H3K36 methylation are also involved in maintaining FLC expression and repressing flowering [54].

Once the plant has reached maturity and environmental conditions are optimal, FLC must be silenced so that flowering can occur. This switch from the active to silent state requires recruitment of $\mathrm{H} 3 \mathrm{~K} 4$ demethylase enzymes and a PRC2 complex that deposits $\mathrm{H} 3 \mathrm{~K} 27 \mathrm{me} 3$, which leads to recruitment of LHP1 and silencing of the gene. In addition, arginine methylation of $\mathrm{H} 3$ and $\mathrm{H} 4$ as well as methylation of $\mathrm{H} 3 \mathrm{~K} 9$ are also important for stable silencing of $F L C$ [54]. Interestingly, H2A.Z remains present and in fact increases in abundance in silenced $F L C$ chromatin, indicating that it is one component that is necessary but insufficient for $F L C$ expression [50]. In order for vegetative growth to resume in the next generation, $F L C$ is reverted to an active state during embryo development, and the cycle continues $[55,56]$.

\section{Plant responses to the environment}

Plants are constantly faced with environmental changes such as temperature, nutrient and water availability, as well as attack by pathogens and herbivores. In recent years a great deal of progress has been made in identifying many of the genes that are responsive to these varied environmental conditions, and also in understanding the role of chromatin alterations in regulating their expression. While some of the histone modifications discussed above are thought to be important for environmental responses, studies of plant responses to temperature, phosphate deficiency, and pathogens have revealed new and unexpected functions of H2A.Z.

In a genetic screen to identify regulators of the response to increased temperature in Arabidopsis, Kumar and Wigge [57] found the ARP6 gene, which encodes an essential component of the SWR1 complex that is required for H2A.Z incorporation into chromatin. The authors found that the set of genes that are normally altered in expression in response to increased temperature were constitutively altered in arp6 mutants grown at normal temperature. Furthermore, they found that H2A.Z nucleosomes were lost from genes after a temperature increase in wild type plants, suggesting that H2A.Z nucleosomes serve as temperature sensors and actually gate the response to increased temperature. In warmer temperatures some genes are upregulated and others are downregulated, thus the role of H2A.Z in modulating transcription seems to depend on the gene context.

Down regulation of expression by H2A.Z has also been observed at phosphate starvation response (PSR) genes, which are induced in response to phosphate deficiency [58]. These genes are normally expressed at very low levels and many have H2A.Z-containing nucleosomes near their TSSs. Interestingly, it was observed that many of the PSR genes are 
highly induced in arp6 mutants, suggesting that H2A.Z serves to reduce expression of these genes. Similarly, gene expression profiling studies have indicated that many of the genes involved in the pathogen response known as systemic acquired resistance (SAR) are also constitutively upregulated in mutants in which the SWR1 complex is non-functional [53].

Collectively, these examples show that H2A.Z is not simply required for induction or highlevel transcription of genes, as it is for $F L C$, but in fact seems to have the opposite effect at some genes. In the case of the warm temperature response, the physical basis of this effect appears to be the general thermal instability of H2A.Z nucleosomes, which would increase exposure of promoter DNA to transcriptional regulatory proteins that dictate the specific response of each gene to increased temperature. Such a mechanism is also likely at play in the case of the PSR and SAR genes.

\section{Conclusions and prospects for the future}

Histone variants and PTMs are generally conserved in multicellular eukaryotes, but these chromatin modifications are diversified in different organisms in terms of the genes they regulate, and consequently the developmental processes they control. Recent progress in the chromatin field has shown that histone variants can have major effects on the physical stability of nucleosomes and therefore may regulate gene expression by modulating DNA exposure, similar to the direct effects of histone acetylation and deacetylation. Histone methylations likely create binding sites for effector proteins that can promote or repress transcription by mechanisms that remain to be fully elucidated. The effects on gene expression of other histone modifications, including phosphorylation and ubiquitylation, are poorly understood.

The transcriptionally active gene state generally correlates with H2A.Z, a number of different PTMs including acetylated H3, H3K4me3, as well as a lack of H3K27me3. Conversely, the silent state appears to require $\mathrm{H} 3 \mathrm{~K} 27 \mathrm{me} 3$, histone deacetylation, and demethylation of H3K4. Each of these states is metastable at a given gene and can be interconverted in response to endogenous and environmental cues. It is this regulated interconversion between active and silent states that allows for precise timing of plant life cycle transitions, such as flowering, and appropriate responses to environmental conditions.

While genome-scale methods have provided clues as to possible roles of histone variants and PTMs in plant gene regulation, important questions remain. In the coming years it will be necessary to gain a better understanding of the specific roles that many PTMs play in the activation and silencing of particular genes during development and in response to the environment. Another rich area of study will be the characterization of chromatin protein families. Many chromatin components including H2A.Z, H3.3, histone modifying enzymes, modification removal enzymes, as well as modification binding proteins are encoded by multi-gene families [6], providing the potential for functional specialization among family members. While in some cases there is evidence for redundancy with these gene families [53,59], it is clear that this is often not the case [60,61]. Thus, deeper functional study of such protein families will be important for understanding the full epigenomic repertoire of plants. Furthermore, intensified studies of rice and maize chromatin are needed in order to understand the commonalities and differences in chromatin-based gene regulation among divergent plant lineages.

In terms of methodology, it is important for plant researchers not only to continue to embrace new genomics technologies that provide genome-scale readouts, but also to perform gene expression and chromatin profiling studies of single cell types. Recently, several technologies have been developed that make possible the profiling of gene 
expression and chromatin in specific plant cell types $[42,62,63]$. As opposed to starting with whole tissue, these approaches have the advantage that the behavior of individual cell types can be monitored, rather than amalgamating signals from multiple cell types in a tissue. This issue cannot be ignored because individual cell types clearly have different gene expression profiles and chromatin features, and also respond to environmental stimuli in different ways [64]. Ultimately, studying the intricate relationships between chromatin alterations and gene expression in individual cell types will illuminate how the genome is reprogrammed during cell differentiation and will also lead to a better understanding of the unique structural and physiological characteristics of each cell type in the plant body.

\section{Acknowledgments}

We thank Paul Talbert for helpful suggestions on improving the manuscript. This work was supported by funding from the Howard Hughes Medical Institute to S.H. and NIH Postdoctoral Fellowship 1F32GM083449 to R.B.D.

\section{References}

* of special interest

** of outstanding interest

1. Kornberg RD. Chromatin structure: a repeating unit of histones and DNA. Science. 1974; 184:868871. [PubMed: 4825889]

2. Luger K, Rechsteiner TJ, Flaus AJ, Waye MM, Richmond TJ. Characterization of nucleosome core particles containing histone proteins made in bacteria. J Mol Biol. 1997; 272:301-311. [PubMed: 9325091]

3. Li B, Carey M, Workman JL. The role of chromatin during transcription. Cell. 2007; 128:707-719. [PubMed: 17320508]

4. Henikoff S. Nucleosome destabilization in the epigenetic regulation of gene expression. Nat Rev Genet. 2008; 9:15-26. [PubMed: 18059368]

5. Talbert PB, Henikoff S. Histone variants--ancient wrap artists of the epigenome. Nat Rev Mol Cell Biol. 2010; 11:264-275. [PubMed: 20197778]

*6. Gendler K, Paulsen T, Napoli C. ChromDB: the chromatin database. Nucleic Acids Res. 2008; 36:D298-302. [PubMed: 17942414] This paper describes a comprehensive database of known and predicted chromatin proteins from many different organisms. This database is useful for informing functional studies as well as for comparative and phylogenetic studies.

7. van Attikum H, Gasser SM. Crosstalk between histone modifications during the DNA damage response. Trends Cell Biol. 2009; 19:207-217. [PubMed: 19342239]

8. Rybaczek D, Bodys A, Maszewski J. H2AX foci in late S/G2- and M-phase cells after hydroxyureaand aphidicolin-induced DNA replication stress in Vicia. Histochem Cell Biol. 2007; 128:227-241. [PubMed: 17636317]

9. Suto RK, Clarkson MJ, Tremethick DJ, Luger K. Crystal structure of a nucleosome core particle containing the variant histone H2A.Z. Nat Struct Biol. 2000; 7:1121-1124. [PubMed: 11101893]

10. Raisner RM, Madhani HD. Patterning chromatin: form and function for H2A.Z variant nucleosomes. Curr Opin Genet Dev. 2006; 16:119-124. [PubMed: 16503125]

11. Raisner RM, Hartley PD, Meneghini MD, Bao MZ, Liu CL, Schreiber SL, Rando OJ, Madhani HD. Histone variant H2A.Z marks the $5^{\prime}$ ends of both active and inactive genes in euchromatin. Cell. 2005; 123:233-248. [PubMed: 16239142]

12. Mavrich TN, Jiang C, Ioshikhes IP, Li X, Venters BJ, Zanton SJ, Tomsho LP, Qi J, Glaser RL, Schuster SC, et al. Nucleosome organization in the Drosophila genome. Nature. 2008; 453:358362. [PubMed: 18408708]

13. Zilberman D, Coleman-Derr D, Ballinger T, Henikoff S. Histone H2A.Z and DNA methylation are mutually antagonistic chromatin marks. Nature. 2008; 456:125-129. [PubMed: 18815594] 
14. Conerly ML, Teves SS, Diolaiti D, Ulrich M, Eisenman RN, Henikoff S. Changes in H2A.Z occupancy and DNA methylation during B-cell lymphomagenesis. Genome Res. 2010

15. Mizuguchi G, Shen X, Landry J, Wu WH, Sen S, Wu C. ATP-driven exchange of histone H2AZ variant catalyzed by SWR1 chromatin remodeling complex. Science. 2004; 303:343-348. [PubMed: 14645854]

16. Malik HS, Henikoff S. Phylogenomics of the nucleosome. Nat Struct Biol. 2003; 10:882-891. [PubMed: 14583738]

17. Tagami H, Ray-Gallet D, Almouzni G, Nakatani Y. Histone H3.1 and H3.3 complexes mediate nucleosome assembly pathways dependent or independent of DNA synthesis. Cell. 2004; 116:5161. [PubMed: 14718166]

18. Drane P, Ouararhni K, Depaux A, Shuaib M, Hamiche A. The death-associated protein DAXX is a novel histone chaperone involved in the replication-independent deposition of H3.3. Genes Dev. 2010; 24:1253-1265. [PubMed: 20504901]

19. Goldberg AD, Banaszynski LA, Noh KM, Lewis PW, Elsaesser SJ, Stadler S, Dewell S, Law M, Guo X, Li X, et al. Distinct factors control histone variant H3.3 localization at specific genomic regions. Cell. 2010; 140:678-691. [PubMed: 20211137]

20. Mito Y, Henikoff JG, Henikoff S. Genome-scale profiling of histone H3.3 replacement patterns. Nat Genet. 2005; 37:1090-1097. [PubMed: 16155569]

21. Deal RB, Henikoff JG, Henikoff S. Genome-wide kinetics of nucleosome turnover determined by metabolic labeling of histones. Science. 2010; 328:1161-1164. [PubMed: 20508129]

22. Henikoff S, Henikoff JG, Sakai A, Loeb GB, Ahmad K. Genome-wide profiling of salt fractions maps physical properties of chromatin. Genome Research. 2009; 19:460-469. [PubMed: 19088306]

23. Jin C, Felsenfeld G. Nucleosome stability mediated by histone variants H3.3 and H2A.Z. Genes Dev. 2007; 21:1519-1529. [PubMed: 17575053]

*24. Jin C, Zang C, Wei G, Cui K, Peng W, Zhao K, Felsenfeld G. H3.3/H2A.Z double variantcontaining nucleosomes mark 'nucleosome-free regions' of active promoters and other regulatory regions. Nat Genet. 2009; 41:941-945. [PubMed: 19633671] This paper shows that nucleosomes containing both H2A.Z and H3.3 are unstable compared to other nucleosomes and are enriched in active promoters.

25. Phelps-Durr TL, Thomas J, Vahab P, Timmermans MC. Maize rough sheath2 and its Arabidopsis orthologue ASYMMETRIC LEAVES1 interact with HIRA, a predicted histone chaperone, to maintain knox gene silencing and determinacy during organogenesis. Plant Cell. 2005; 17:28862898. [PubMed: 16243907]

26. Rando OJ, Chang HY. Genome-wide views of chromatin structure. Annu Rev Biochem. 2009; 78:245-271. [PubMed: 19317649]

27. Berger SL. The complex language of chromatin regulation during transcription. Nature. 2007; 447:407-412. [PubMed: 17522673]

28. Fuchs J, Demidov D, Houben A, Schubert I. Chromosomal histone modification patterns--from conservation to diversity. Trends Plant Sci. 2006; 11:199-208. [PubMed: 16546438]

*29. Eskeland R, Leeb M, Grimes GR, Kress C, Boyle S, Sproul D, Gilbert N, Fan Y, Skoultchi AI, Wutz A, et al. Ring1B compacts chromatin structure and represses gene expression independent of histone ubiquitination. Molecular Cell. 2010; 38:452-464. [PubMed: 20471950] The data presented in this paper show that Polycomb silencing occurs through chromatin compaction in vivo.

30. Francis NJ, Kingston RE, Woodcock CL. Chromatin compaction by a polycomb group protein complex. Science. 2004; 306:1574-1577. [PubMed: 15567868]

31. Pray-Grant MG, Daniel JA, Schieltz D, Yates JR 3rd, Grant PA. Chd1 chromodomain links histone H3 methylation with SAGA- and SLIK-dependent acetylation. Nature. 2005; 433:434-438. [PubMed: 15647753]

32. Sims RJ 3rd, Millhouse S, Chen CF, Lewis BA, Erdjument-Bromage H, Tempst P, Manley JL, Reinberg D. Recognition of trimethylated histone $\mathrm{H} 3$ lysine 4 facilitates the recruitment of transcription postinitiation factors and pre-mRNA splicing. Mol Cell. 2007; 28:665-676. [PubMed: 18042460] 
33. Santos-Rosa H, Schneider R, Bannister AJ, Sherriff J, Bernstein BE, Emre NC, Schreiber SL, Mellor J, Kouzarides T. Active genes are tri-methylated at K4 of histone H3. Nature. 2002; 419:407-411. [PubMed: 12353038]

*34. Zhang X, Bernatavichute YV, Cokus S, Pellegrini M, Jacobsen SE. Genome-wide analysis of mono-, di- and trimethylation of histone H3 lysine 4 in Arabidopsis thaliana. Genome Biol. 2009; 10:R62. [PubMed: 19508735] The authors report the distributions of H3 methylated to varying extents on K4 across the genome. This study begins to parse out the different roles of each methylation state as well as the connections between H3K4 methylation, K3K27 methylation, and DNA methylation.

*35. He G, Zhu X, Elling AA, Chen L, Wang X, Guo L, Liang M, He H, Zhang H, Chen F, et al. Global epigenetic and transcriptional trends among two rice subspecies and their reciprocal hybrids. Plant Cell. 2010; 22:17-33. [PubMed: 20086188] This paper reports the first large scale study of the genome-wide distributions and relationships between mRNAs, small RNAs, histone modifications, and DNA methylation in rice.

**36. Wang X, Elling AA, Li X, Li N, Peng Z, He G, Sun H, Qi Y, Liu XS, Deng XW. Genome-Wide and Organ-Specific Landscapes of Epigenetic Modifications and Their Relationships to mRNA and Small RNA Transcriptomes in Maize. Plant Cell. 2009; 21:1053-1069. [PubMed: 19376930] A genome-scale analysis of the distributions and relationships between mRNAs, small RNAs, histone modifications, and DNA methylation in Maize. This study reveals general principles of epigenome organization in Maize and demonstrates the power of deep sequencing for profiling large and repetitive genomes.

37. Ruthenburg AJ, Allis CD, Wysocka J. Methylation of lysine 4 on histone H3: intricacy of writing and reading a single epigenetic mark. Mol Cell. 2007; 25:15-30. [PubMed: 17218268]

38. Iwase S, Lan F, Bayliss P, de la Torre-Ubieta L, Huarte M, Qi HH, Whetstine JR, Bonni A, Roberts TM, Shi Y. The X-linked mental retardation gene SMCX/JARID1C defines a family of histone H3 lysine 4 demethylases. Cell. 2007; 128:1077-1088. [PubMed: 17320160]

39. Schwartz YB, Pirrotta V. Polycomb silencing mechanisms and the management of genomic programmes. Nat Rev Genet. 2007; 8:9-22. [PubMed: 17173055]

40. Alvarez-Vargas, R. The Arabidopsis Book. American Society of Plant Biologists; Rockville, MD: 2010. Regulation by polycomb and trithorax group proteins in Arabidopsis. doi: 10.1199/tab.0128, http://www.aspb.org/publications/arabidopsis/

41. Zhang X, Clarenz O, Cokus S, Bernatavichute YV, Pellegrini M, Goodrich J, Jacobsen SE. Wholegenome analysis of histone H3 lysine 27 trimethylation in Arabidopsis. PLoS Biol. 2007; 5:e129. [PubMed: 17439305]

**42. Deal RB, Henikoff S. A simple method for gene expression and chromatin profiling of individual cell types within a tissue. Dev Cell. 2010; 18:1030-1040. [PubMed: 20627084] A method for affinity isolation of nuclei from specific cell types is described in this paper. We show that this method can be used to determine genome-wide gene expression and chromatin profiles of individual cell types.

43. Zhang X, Germann S, Blus BJ, Khorasanizadeh S, Gaudin V, Jacobsen SE. The Arabidopsis LHP1 protein colocalizes with histone H3 Lys27 trimethylation. Nature Structural \& Molecular Biology. 2007; 14:869-871.

44. Turck F, Roudier F, Farrona S, Martin-Magniette M-L, Guillaume E, Buisine N, Gagnot S, Martienssen RA, Coupland G, Colot V. Arabidopsis TFL2/LHP1 specifically associates with genes marked by trimethylation of histone H3 lysine 27. PLoS Genet. 2007; 3:e86. [PubMed: 17542647]

**45. Xu L, Shen WH. Polycomb silencing of KNOX genes confines shoot stem cell niches in Arabidopsis. Curr Biol. 2008; 18:1966-1971. [PubMed: 19097900] The authors use genetic and molecular analyses to identify a previously unrecognized PRC1-like complex in Arabidopsis that is involved in KNOX gene silencing. These results shed light on the mechanisms of Polycomb silencing in plants.

**46. Calonje M, Sanchez R, Chen L, Sung ZR. EMBRYONIC FLOWER1 participates in polycomb group-mediated AG gene silencing in Arabidopsis. Plant Cell. 2008; 20:277-291. [PubMed: 18281509] The plant-specific EMF1 protein is shown to effect Polycomb silencing in 
conjunction with the PRC2 complex. This indicates that there is at least one other mechanism for Polycomb silencing in plants besides the PRC1-like complex described in [45*].

47. He Y, Doyle MR, Amasino RM. PAF1-complex-mediated histone methylation of FLOWERING LOCUS C chromatin is required for the vernalization-responsive, winter-annual habit in Arabidopsis. Genes Dev. 2004; 18:2774-2784. [PubMed: 15520273]

48. Oh S, Zhang H, Ludwig P, van Nocker S. A mechanism related to the yeast transcriptional regulator Paf1c is required for expression of the Arabidopsis FLC/MAF MADS box gene family. Plant Cell. 2004; 16:2940-2953. [PubMed: 15472079]

49. Tamada Y, Yun J, Chul Woo S, Amasino R. ARABIDOPSIS TRITHORAX-RELATED7 Is Required for Methylation of Lysine 4 of Histone $\mathrm{H} 3$ and for Transcriptional Activation of FLOWERING LOCUS C. Plant Cell. 2009

50. Deal RB, Topp CN, McKinney EC, Meagher RB. Repression of flowering in Arabidopsis requires activation of FLOWERING LOCUS C expression by the histone variant H2A.Z. Plant Cell. 2007; 19:74-83. [PubMed: 17220196]

51. Lázaro A, Gómez-Zambrano A, López-González L, Piñeiro M, Jarillo JA. Mutations in the Arabidopsis SWC6 gene, encoding a component of the SWR1 chromatin remodelling complex, accelerate flowering time and alter leaf and flower development. J Exp Bot. 2008; 59:653-666. [PubMed: 18296430]

52. March-Díaz R, García-Domínguez M, Florencio FJ, Reyes JC. SEF, a new protein required for flowering repression in Arabidopsis, interacts with PIE1 and ARP6. Plant Physiol. 2007; 143:893901. [PubMed: 17142478]

**53. March-Díaz R, García-Domínguez M, Lozano-Juste J, León J, Florencio FJ, Reyes JC. Histone H2A.Z and homologues of components of the SWR1 complex are required to control immunity in Arabidopsis. Plant J. 2008; 53:475-487. [PubMed: 17988222] The authors show that the SWR1 complex and H2A.Z are responsible for the regulation of a class of genes specifically involved in pathogen response. The results also demonstrate that two of the three H2A.Z isoforms in Arabidopsis are functionally redundant.

54. He Y. Control of the transition to flowering by chromatin modifications. Molecular Plant. 2009; 2:554-564. [PubMed: 19825638]

*55. Sheldon CC, Hills MJ, Lister C, Dean C, Dennis ES, Peacock WJ. Resetting of FLOWERING LOCUS C expression after epigenetic repression by vernalization. Proc Natl Acad Sci USA. 2008; 105:2214-2219. [PubMed: 18250331] See annotation for [56*].

*56. Choi J, Hyun Y, Kang MJ, In Yun H, Yun JY, Lister C, Dean C, Amasino RM, Noh B, Noh YS, et al. Resetting and regulation of Flowering Locus $\mathrm{C}$ expression during Arabidopsis reproductive development. Plant J. 2009; 57:918-931. [PubMed: 19121105] These two papers demonstrate that FLC expression is restored during embryonic development. It was previously assumed that the gene was reactivated at some point after flowering, but the timing was unknown.

**57. Kumar SV, Wigge PA. H2A.Z-Containing Nucleosomes Mediate the Thermosensory Response in Arabidopsis. Cell. 2010; 140:136-147. [PubMed: 20079334] This paper demonstrates that plant responses to increased temperature are modulated through the thermal instability properties of H2A.Z nucleosomes. The data show that H2A.Z has both positive and negative efects on transcription.

58. Smith AP, Jain A, Deal RB, Nagarajan VK, Poling MD, Raghothama KG, Meagher RB. Histone H2A.Z regulates the expression of several classes of phosphate starvation response genes but not as a transcriptional activator. Plant Physiol. 2010; 152:217-225. [PubMed: 19897606]

59. Jeong J-H, Song H-R, Ko J-H, Jeong Y-M, Kwon YE, Seol JH, Amasino RM, Noh B, Noh Y-S. Repression of FLOWERING LOCUS T chromatin by functionally redundant histone H3 lysine 4 demethylases in Arabidopsis. PLoS ONE. 2009; 4:e8033. [PubMed: 19946624]

*60. Saleh A, Alvarez-Venegas R, Yilmaz M, Le O, Hou G, Sadder M, Al-Abdallat A, Xia Y, Lu G, Ladunga I, et al. The highly similar Arabidopsis homologs of trithorax ATX1 and ATX2 encode proteins with divergent biochemical functions. Plant Cell. 2008; 20:568-579. [PubMed: 18375658] See annotation for [61*].

*61. Hark AT, Vlachonasios KE, Pavangadkar KA, Rao S, Gordon H, Adamakis I-D, Kaldis A, Thomashow MF, Triezenberg SJ. Two Arabidopsis orthologs of the transcriptional coactivator ADA2 have distinct biological functions. Biochim Biophys Acta. 2009; 1789:117-124. 
[PubMed: 18929690] The data presented in each of these papers show that closely related chromatin modifying enzymes can have distinct biological functions.

62. Birnbaum K, Jung JW, Wang JY, Lambert GM, Hirst JA, Galbraith DW, Benfey PN. Cell typespecific expression profiling in plants via cell sorting of protoplasts from fluorescent reporter lines. Nat Methods. 2005; 2:615-619. [PubMed: 16170893]

**63. Zhang C, Barthelson RA, Lambert GM, Galbraith DW. Global characterization of cell-specific gene expression through fluorescence-activated sorting of nuclei. Plant Physiol. 2008; 147:3040. [PubMed: 18354040] This paper describes a method for isolating nuclei from specific cell types by fluorescence-activated cell sorting. The authors demonstrate that these nuclei can be used for gene expression profiling in individual cell types.

64. Dinneny JR, Long TA, Wang JY, Jung JW, Mace D, Pointer S, Barron C, Brady SM, Schiefelbein J, Benfey PN. Cell identity mediates the response of Arabidopsis roots to abiotic stress. Science. 2008; 320:942-945. [PubMed: 18436742] 

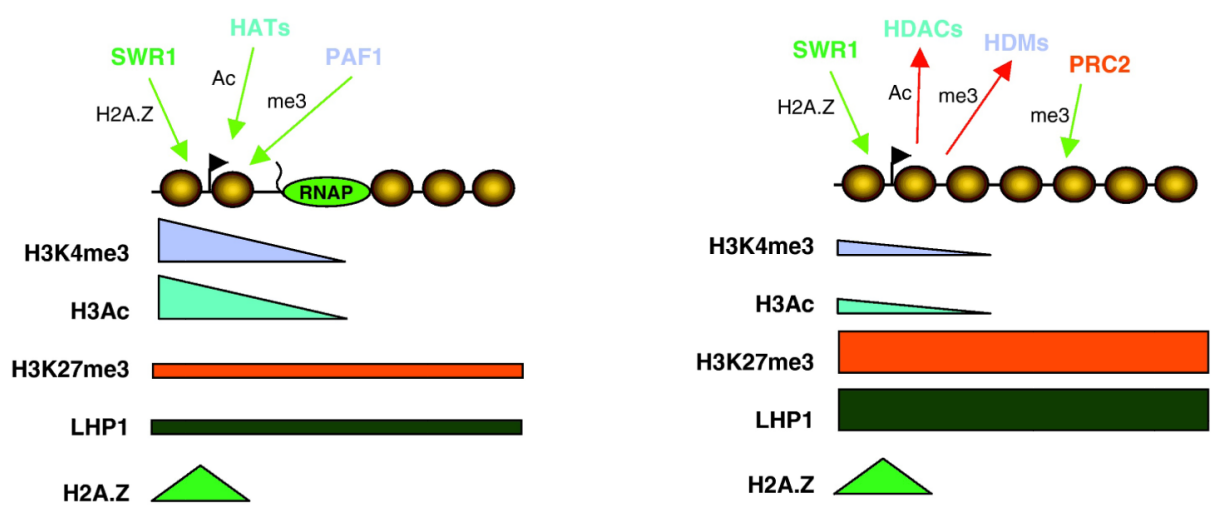
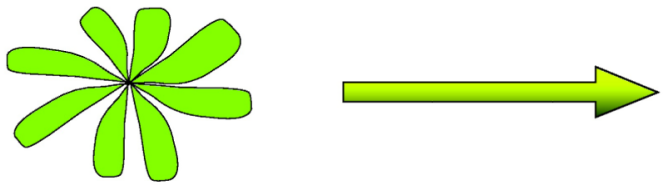

Vegetative growth FLC "ON"

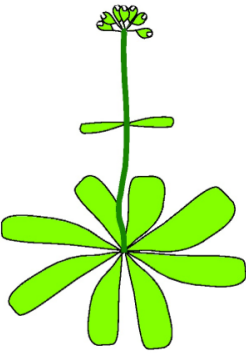

Flowering FLC "OFF" Current Opinion in Plant Biology

Figure 1. Chromatin-level regulation of the $F L C$ gene and the transition to flowering. A simplified depiction is shown of the main chromatin factors that promote activation and silencing of FLC to control the developmental phase of the plant. In the vegetative growth state, represented in the left panel, the FLC gene is expressed and the encoded protein represses genes that initiate flowering. Chromatin at the FLClocus is depicted at top, where brown circles represent nucleosomes and the TSS is shown as a black flag on the gene. FLC chromatin is made permissive for transcription by RNA polymerase (RNAP) through the action of the SWR1 complex which incorporates H2A.Z into nucleosomes around the TSS, histone acetyltransferase complexes (HATs) which add acetyl groups (Ac) to histones, and the PAF1 complex which trimethylates (me3) H3K4 as it travels with RNAP. The distribution and abundance of each chromatin mark is depicted below the locus diagram. In the active state $\mathrm{H} 3 \mathrm{~K} 4 \mathrm{me} 3$ and $\mathrm{H} 3$ acetylation (H3Ac) are high at the $5^{\prime}$ end of the gene whereas the levels of H3K27me3 and LHP1, the silencing protein that recognizes H3K27me3, are low throughout. H2A.Z is incorporated into nucleosomes around the TSS. $F L C$ is silenced once the plant matures and environmental conditions are permissive, allowing expression of the flowering induction genes and production of an inflorescence. Silencing occurs through the combined action of histone deacetylases (HDACs) which remove acetyl groups from histones, histone demethylases (HDMs) which remove the methyl groups from $\mathrm{H} 3 \mathrm{~K} 4$, and the PRC2 complex which trimethylates H3K27. Once the H3K27me3 mark is imparted, it is recognized and bound by LHP1 which promotes stable silencing of the gene. H2A.Z continues to be incorporated into upstream nucleosomes by SWR1. When flowering and fertilization is complete, FLC must be reactivated in the embryo so that vegetative growth will commence upon germination. Incorporation of H2A.Z into the silent FLC chromatin appears to be required for this reactivation. 